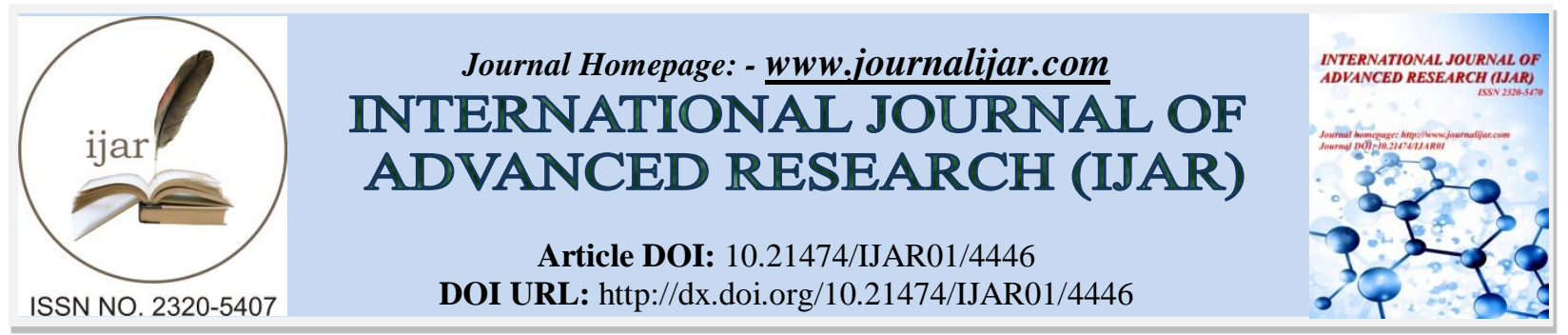

RESEARCH ARTICLE

\title{
CHEMICAL ASPECTS OF ANTIANXIETY DRUGS.
}

\author{
D.K.Awasthi ${ }^{1}$ and Gyanendra Awasthi ${ }^{2}$ \\ 1. Department of Chemistry 'Sri.J.N.P.G.College,Lucknow,U.P. India \\ 2. Department of Bio-Chemistry, Dolphin Institute of Bio-Medical Sciences Dehradoon,U.K. India.
}

\section{Manuscript Info}

(........................

Manuscript History

Received: 11 April 2017

Final Accepted: 13 May 2017

Published: June 2017

\section{Abstract}

These drugs are used for the treatment of mental disorder antianxiety Drugs are chemicallyMeprobamate and benzodiazepines Anxiety is an emotional condition. It is related to uneasiness, unpleasant, discomfort and fear for future.Antianxietydrugs are mild CNS depressants, are used to control mild or severe anxiety.AntianxietyDrugsareBenzodiazepines, Azapirones, Sedative Antihistamine and. $\beta$-Blocker

Copy Right, IJAR, 2017,. All rights reserved.

\section{Introduction:-}

These drugs are used for the treatment of mental disorder. Anxiety is an emotional condition. It is related to uneasiness, unpleasant, discomfort and fear for future.Antianxietydrugs is mild CNS depressants, are used to control mild or severe anxiety. These are very useful to produce restful state to mind without disturbing normal mental or physical functions. Antianxiety drugs are chemically Meprobamate and benzodiazepines

\section{Antianxiety Drugs:-}

Types ofAntianxietyDrugs:-1.Benzodiazepines, 2.Azapirones, 3.Sedative

Antihistamine, 4. $\beta$-Blocker and5. Meprobamate

\section{Drugs and Synthesis:-}

Benzodiazepines:-

These are more effective drugs, without producing global CNS depression, have been justified for the treatment of anxiety and stress. More effective than Barbiturates.GABA (Gamma amino butyric acid) is a neurotransmitter. It has been found GABA increases high affinity binding ofBenzodiazepines.It has been found at high doses of

Benzodiazepines affect all neurotransmitter present in central nervous system.

They may produce their effect primarily by enhancing GABA ergic transmission provided an explanation for the various secondary alternations induced by these drugs in other transmittersystems.GABA acts on two differentreceptortypes. The action of Benzodiazepines appears to be restricted to synaptic effects of GABA which are mediated by the so-calledGABA $\mathrm{A}_{\mathrm{A}}$ receptors.

\section{Chlordiazepoxide:-}

It is a first Benzodiazepine drugs which is used preferably for the treatment of chronic anxiety, its absorption is slow and produces a smooth long lasting effect. It has poor anticonvulsant action. 


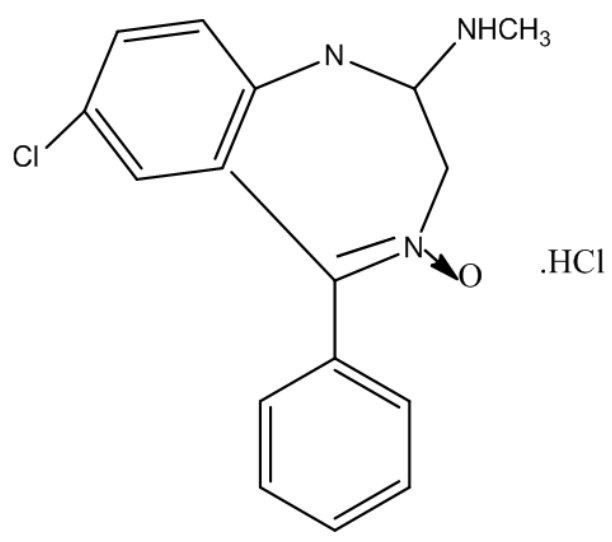

\section{Chlordiazepoxide Hydrochloride}

\section{Diazepam:-}

The is more effective drug, is used in acute panic states and anxiety. It is rapidly absorbed. It is seven member hetero cyclic compound having two nitrogen and three double bond 1,4 benzodiazepine contains benzene ring which is fused to 1,4 diazepine. 1,4 position represent to nitrogen atom. It is rapidly absorbed drug and produces a brief initial phase of strong action.

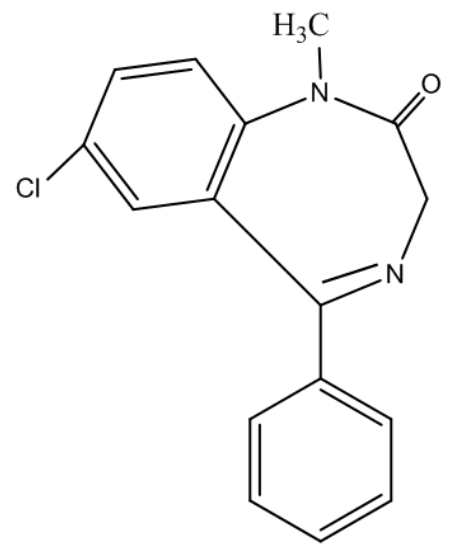

Diazepam 


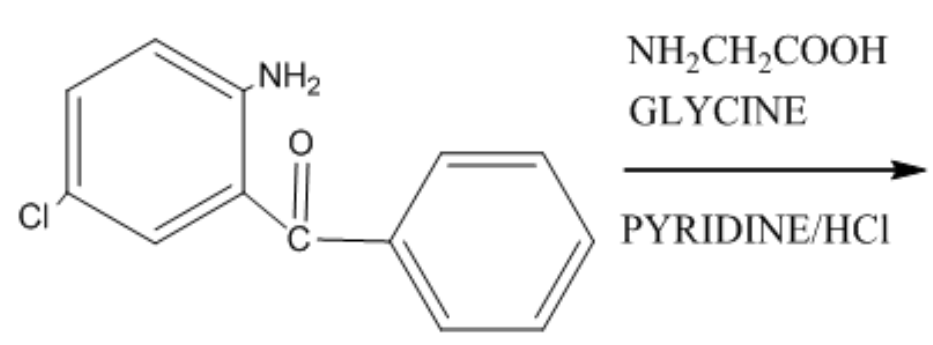

2-amino-5-chloro benzophenone
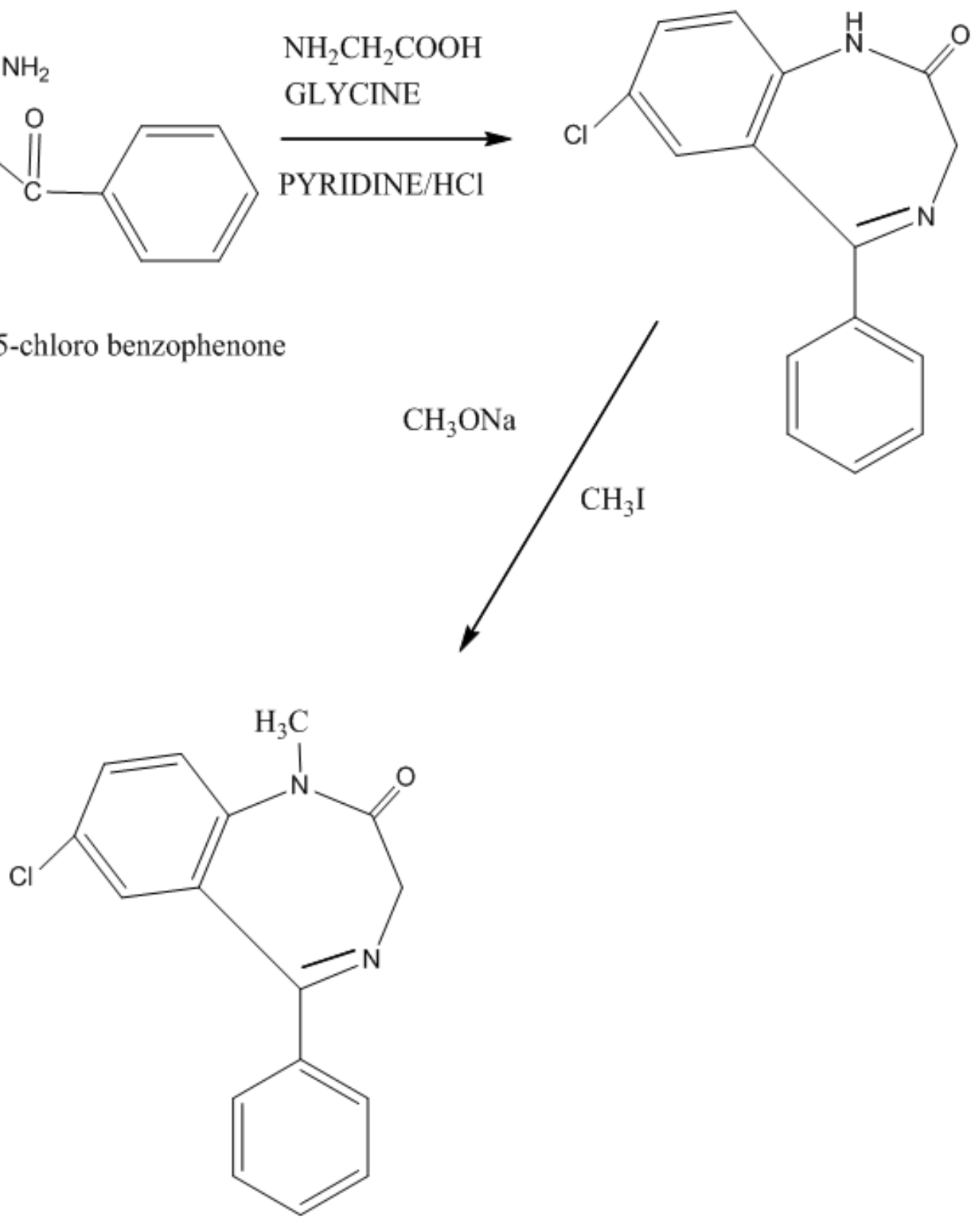

\section{Diazepam}

\section{Lorazepam:-}

It is recommended for short lived anxiety states, psychosomatic diseases, obsessive compulsive neurosis and tension syndrome. It is good sedative drug. It is the 0nly benzodiazepine which is recommended for intramuscular use. It has slow absorption when is given orally, it is less lipid soluble drug, rate of entry in brain is much slower. 

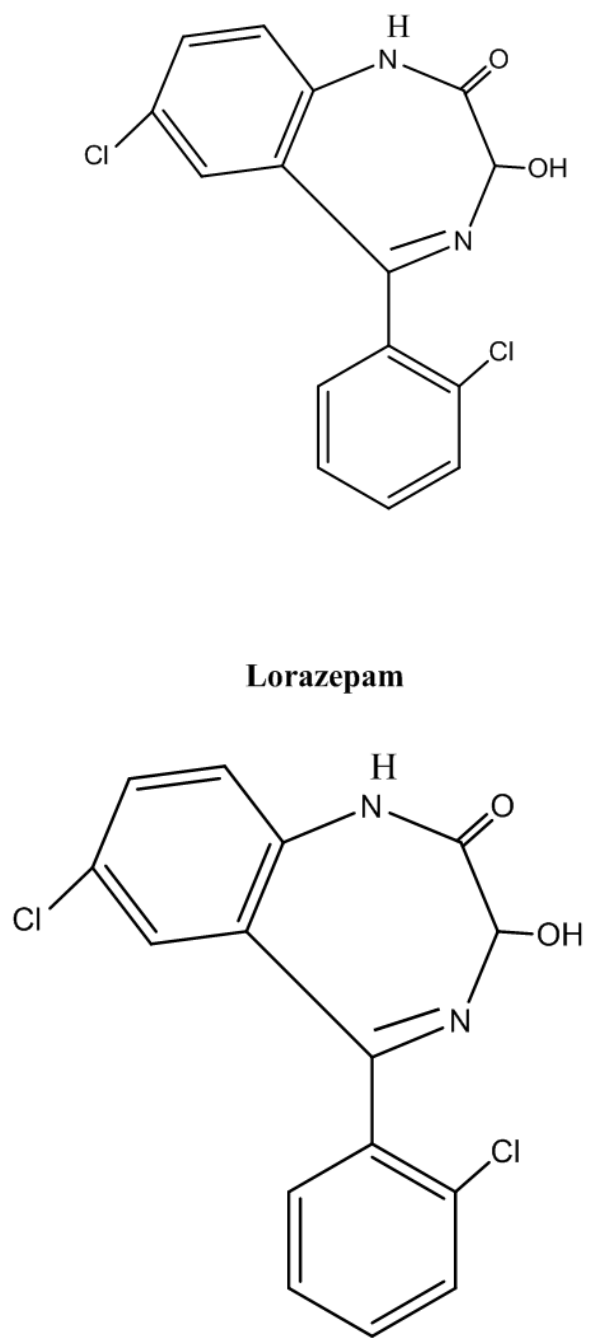

\section{Lorazepam}

\section{Oxazepam:-}

Oxazepam is a slowly absorbed drug and its rate of entry in is slow. It has been used mainly in short lasting anxiety states. Its hepatic metabolism is not significant and duration of action is short. Hence it is preferably given to older patients who have suffered with liver disease. Its metabolism is facilitated by the 3 hydroxy functions; which allows for direct conjugation as the glucuronide and excretion in the urine. Basic structure of Oxazepam and Lorazepam are related to each other. 


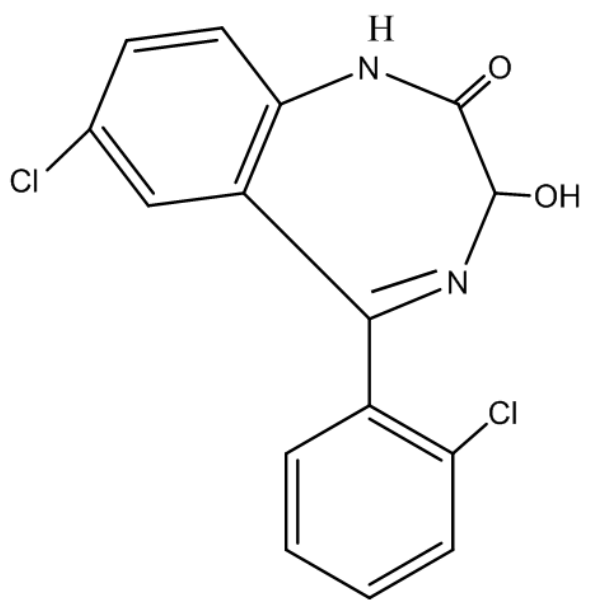

\section{Synthesis:-}

\section{Lorazepam}
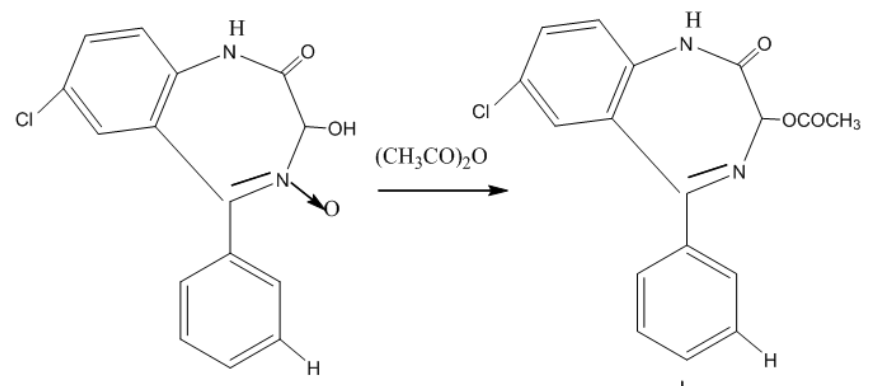

Demoxepam

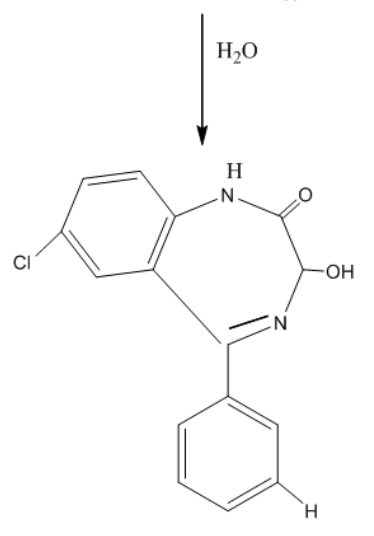

Oxazepam

\section{Alprazolam:-}

Alprazolam is a high potency anti anxiety benzodiazepine. This drug is especially useful for the treatment of mild depression. It has mood elevation property. It provides good response in the treatment of severe anxiety and autonomic symptom, causes a little drowsiness. 


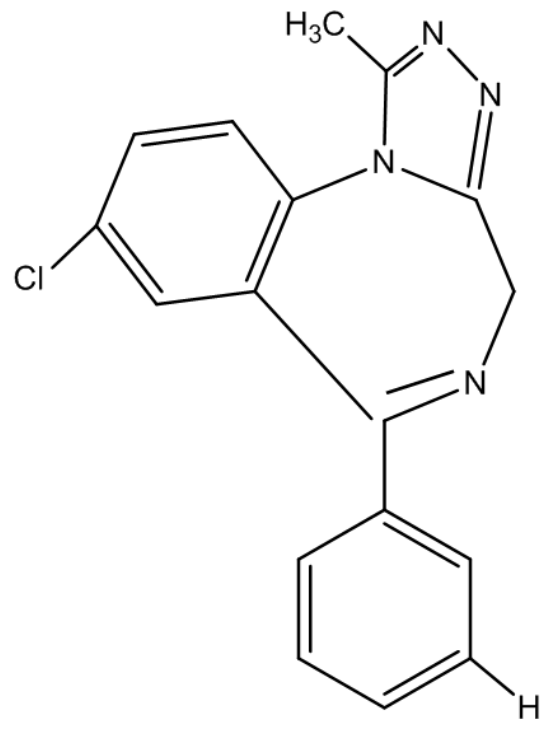

\section{Synthesis:-}

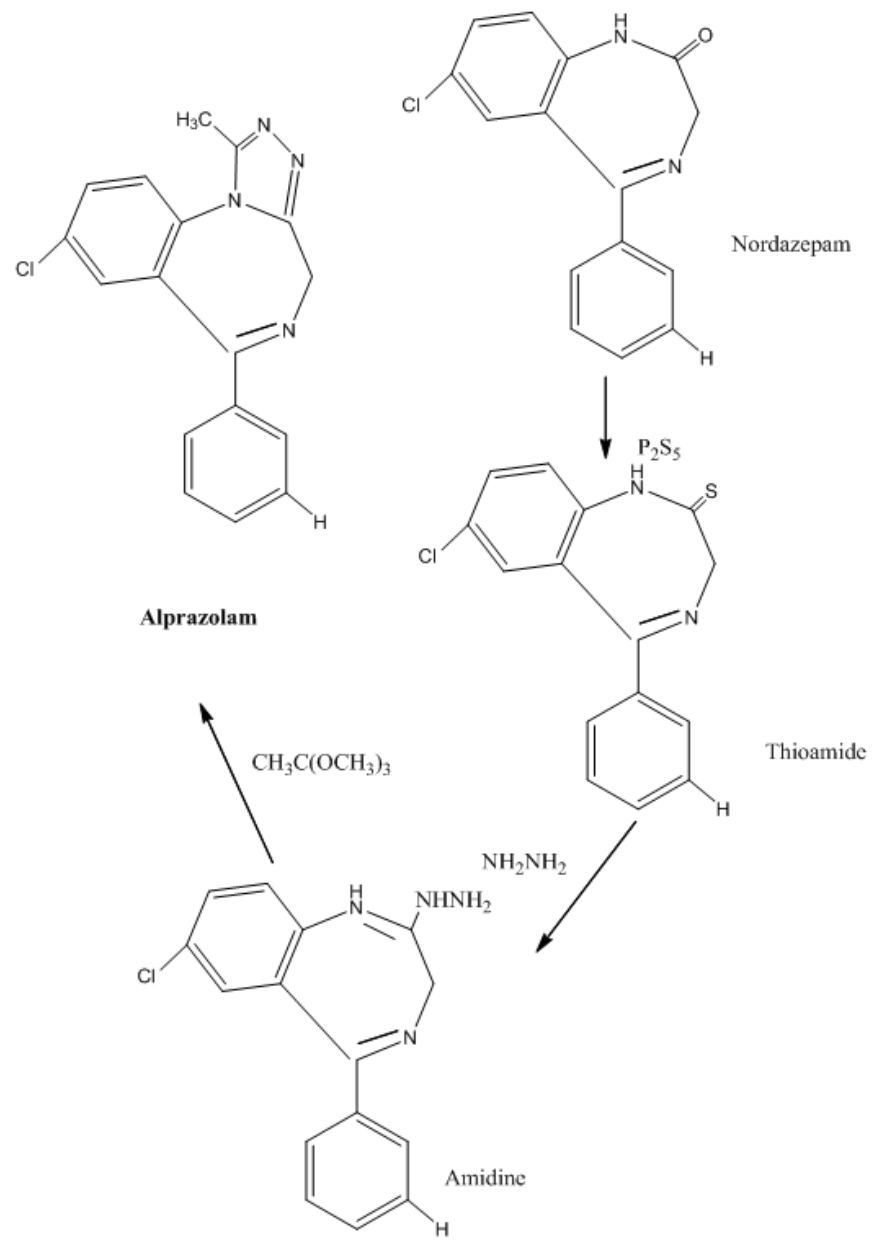

Alprazolam 


\section{Flurazepam:-}

It is suitable for a patient who has frequently night awakening and in whom some daytime sedation is acceptable'

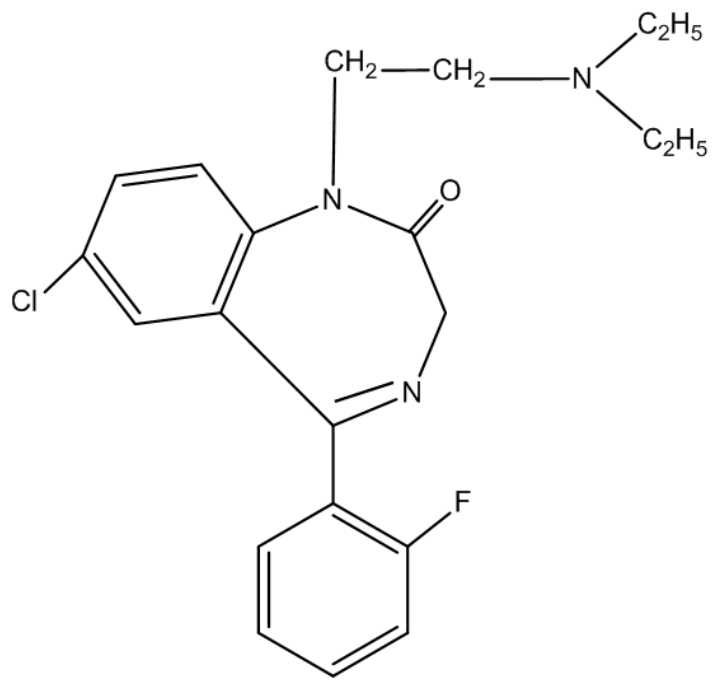

\section{Flurazepam}

\section{Buspirone:-}

Buspirone is the first azapirone antianxiety drug, has no muscles relaxant or anticonvulasantactivity.It does not produce physical dependence or tolerence, which gives relief from mild to moderate anxiety, but it is ineffective in severe cases compulsive disorders, dors not produce significant sedation or functional impairment. The therapeutic effect from buspiron is gained slowly. It is rapidly absorbable drug, does not interact with central nervous system depressants.Itcreats side effect which are minor like light headeac,nausea,dizziness and sometimes excitement. It may cause rise in blood pressure particular in patients on (MAO)i.e monoamine oxidase inhibitors.

Mode of action of this drug is not known, but may be dependent on its selective partial agonistic action on 5$\mathrm{HT}_{1 \mathrm{~A}}\left(5\right.$-hydroxy tryptamine)receptors. By stimulating presynaptic5-HT $\mathrm{HA}_{1 \mathrm{~A}}$ autoreceptors, it synaptic 5-HT $\mathrm{H}_{1 \mathrm{~A}}$ receptors has also been reported. After long term treatment, adaptive reduction in cortical5-HT ${ }_{2}$ receptors may occur.Buspirone consists of weak dopamine $\mathrm{D}_{2}$ blocking action, and it has no psychotic or extra pyramidal effects. 


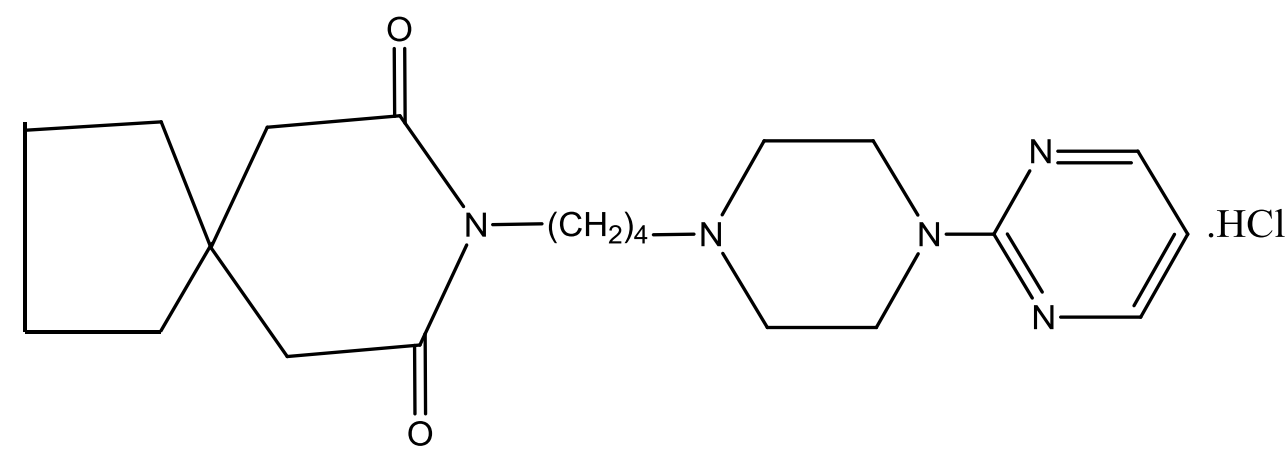

\section{Buspirone}

\section{SedativeAntihistaminicDrug:-}

HydroxyzineisaH1antihistaminicwithsedative, antiemetic, antimucarinic and spasmolytic drug, used in the treatment of urticarial and pruritus.It is claimed to have anti anxiety action, but its sedation is well marked, and may be used in reactive anxiety.

\section{B-Blockers:-}

Propranolol is a B-Blockers drug which helps anxious patients havingtroublehighbloodpressure, shaking, gastrointestinalhurrying, palpitation,tremor,examinationfear,unaccustomed public appearance. Etc.The anxiety is due to over sympathetic over activity. This drug acts as cutting vicious cycle and provides symptomatic relief. does not affect psychological symptoms such as worry, fear and tension. It suppresses anxiety in short term stressful situations, but this is due to peripheral rather than specific central action. Long term use o relatively high doses of propranolol produces changes in subtilebehaviour,forgetfulness and dreaming with nightmares.Gastrointestinalupset, lack of drive and rarely hallucinations are common side effects of propranolol.It is well absorbed after oral administration, quiet soluble in lipids and can easily penetrate into the brain.

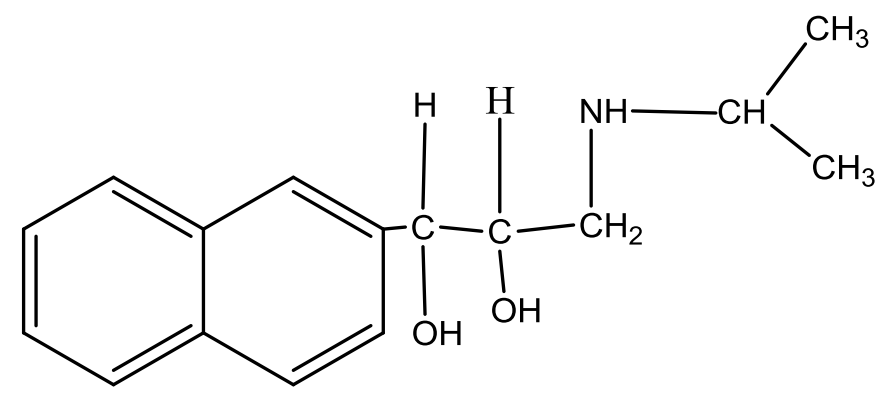

\section{Propranolol}

\section{Meprobamate:-}

It is 2,2-di(carbamoyloxymethyl)pentane Which acts as mild tranquilliser drug havinh some anticonvulsant and muscles relaxant properties. It finds use in the treatment of anxiety and tension but it is less effective than the benzodiazepines. 


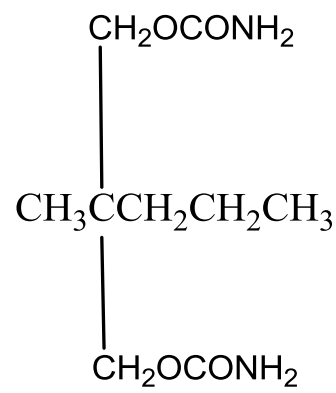

\section{Meprobamate}

Meprobamate
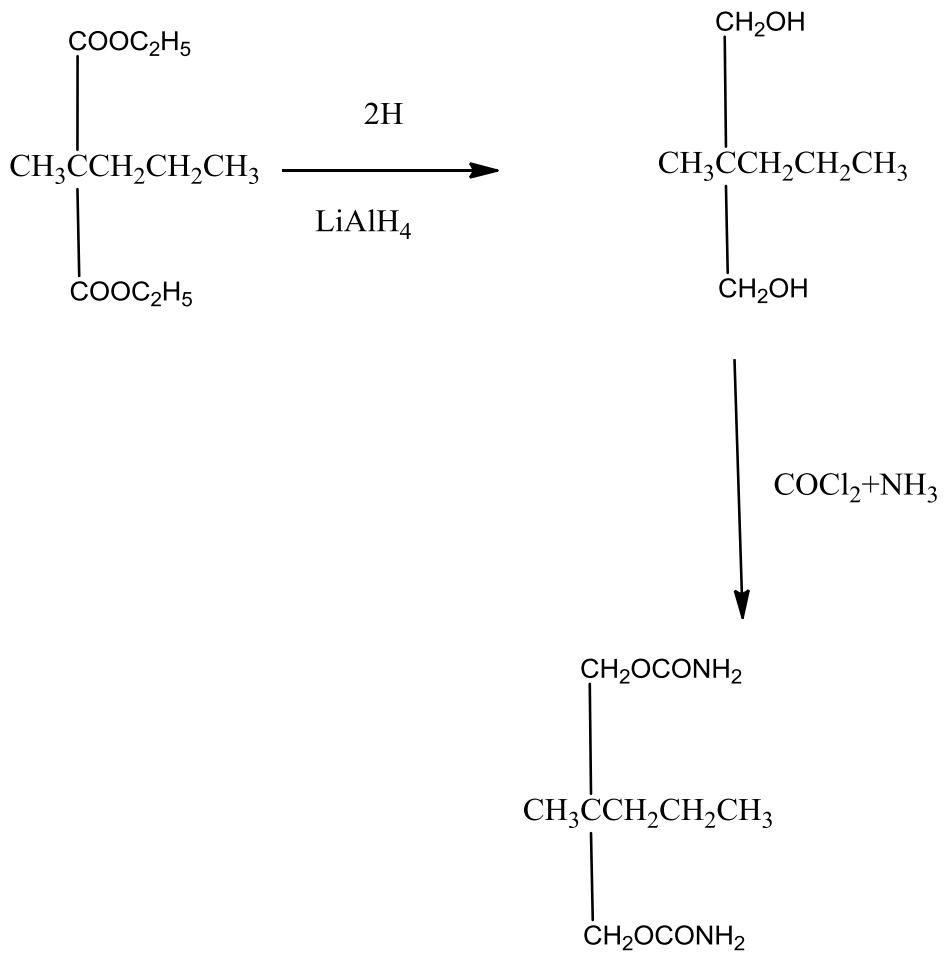

Meprobamate 


\section{Zopiclone:-}

It is a newer Non- Benzodiazepine drug which is cyclopyrrolone hypnotic andit is an agonist at $\mathrm{GABA}_{\mathrm{A}}$ receptor and potentiates GABA by binding to a site other than that of benzodiazepine, does not disturbed sleep architecture or hangover.Short term treatment of insomnia can be obtained by this drug.

\section{Zopiclone}

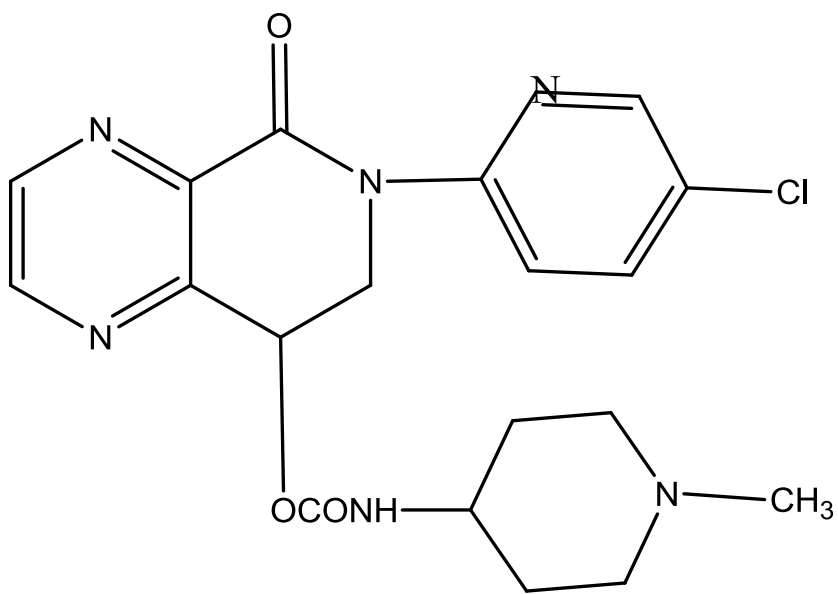

\section{Zopiclone}

\section{Conclusion:-}

Anxiety is a universal phenomenon. When anxiety exists in severe form and persists ,it should be treated only with drugs The established drugs of anxiety are benzodiazepines and buspiron.Benzodiazepines drugs should be used in small doses, in acute anxiety these are responedbetter,are given in low doses in addition to specific drugs to the patients suffering from hypertension,ulcerativecolitis,irritablebowel,pepticulcer,angianapectorisand gatroesophagealreflux.These drugs should not be given for long time.Buspirone is non sedativedrug,is given less severe anxiety.

\section{References:-}

1. J.H.Hyttel, J.Arnt, K.P.Bogeso, CRS Hand book of Stereo isomers: Drugs in Psycopharmacology, CRC1984.

2. R.F.Schmidt, Fundamental of Neurophysiological, NewYork, Springer Verlog,2nded1978.

3. D.J.Greenbiat, R.I.Shader, Benzodiazepines in clinical practice, New YORK, RavenPress, 1974.

4. L.H.Sternback et al; Drugs affecting the central nervous system, vol.2,A.Burger New york,Marcel Dekker,1968.

5. Alka Gupta Medicinal Chemistry PragatiPrakshan India. 